\title{
Basal cell carcinoma: Comprehensive clinical and histopathological aspects, novel imaging tools and therapeutic approaches (Review)
}

\author{
ELENA NICULET ${ }^{1,2^{*}}$, MIHAELA CRAESCU $^{1,3}$, LAURA REBEGEA $^{3,4}$, CARMEN BOBEICA $^{1}$, \\ FLORENTINA NASTASE ${ }^{4 *}$, GABRIELA LUPASTEANU ${ }^{5,6}$, DANIELA JICMAN STAN ${ }^{7,8 *}$, \\ VALENTIN CHIONCEL ${ }^{9,10}$, LUCRETIA ANGHEL ${ }^{11}$, MIHAELA LUNGU ${ }^{11}$ and ALIN LAURENTIU TATU ${ }^{11-14}$
}

${ }^{1}$ Department of Morphological and Functional Sciences, Faculty of Medicine and Pharmacy, 'Dunarea de Jos' University, 800010 Galați; Departments of ${ }^{2}$ Pathology and ${ }^{3}$ Clinical Radiotherapy, 'Sfantul Apostol Andrei' Emergency Clinical Hospital, 800578 Galați; ${ }^{4}$ Department of Neuropsychomotor Rehabilitation, 'Sf. Ioan' Clinical Hospital for Children, 800487 Galați; ${ }^{5}$ Department of Infectious Diseases, 'Sf. Cuvioasa Parascheva' Clinical Hospital of Infectious Diseases, 800179 Galați; ${ }^{6}$ Medical Doctoral School, ‘Ovidius' University, 900573 Constanta; ${ }^{7}$ Department of Otorhinolaryngology, 'Sfantul Apostol Andrei' Emergency Clinical Hospital, 800578 Galați; ${ }^{8}$ Biomedical Doctoral School, Faculty of Medicine and Pharmacy, 'Dunarea de Jos' University of Galați, 800010 Galați; ${ }^{9}$ Department of Cardio-Thoracic Pathology,

'Carol Davila' University of Medicine and Pharmacy, 020021 Bucharest; ${ }^{10}$ Department of Clinical Cardiology,

'Bagdasar Arseni' Emergency Hospital, 041915 Bucharest; ${ }^{11}$ Department of Clinical Medicine, Faculty of Medicine and Pharmacy, 'Dunarea de Jos' University, 800010 Galați; ${ }^{12}$ Department of Dermatology, 'Sfanta Cuvioasa Parascheva'

Clinical Hospital of Infectious Diseases, 800179 Galați; ${ }^{13}$ Research Center in the Field of Medical and

Pharmaceutical Sciences, ReFORM-UDJ, 'Dunărea de Jos' University; ${ }^{14}$ Multidisciplinary Integrated Center of

Dermatological Interface Research MIC-DIR (Centrul Integrat Multidisciplinar de Cercetare de Interfata Dermatologica - CIM-CID), 'Dunărea de Jos’ University, 800010 Galați, Romania

Received August 6, 2021; Accepted September 6, 2021

DOI: $10.3892 / \mathrm{etm} .2021 .10982$

\begin{abstract}
Basal cell carcinoma (BCC) is one of the most common malignant tumors worldwide, involving the skin. It is also part of keratinocyte carcinomas, alongside its

Correspondence to: Dr Mihaela Craescu or Dr Carmen Bobeica, Department of Morphological and Functional Sciences, Faculty of Medicine and Pharmacy, 'Dunarea de Jos' University, 35 Al. I. Cuza Street, 800010 Galați, Romania

E-mail:dr.craescumihaela@yahoo.ro

E-mail: carmenbobeica1@gmail.com

${ }^{*}$ Contributed equally
\end{abstract}

Abbreviations: BCC, basal cell carcinoma; WHO, World Health Organization; PNI, perineural invasion; UV, ultraviolet; PTCH1, patched tumor suppressor gene $1 ; \mathrm{PTCH} 2$, patched tumor suppressor gene 2; HIV, human immunodeficiency virus; IL-6, interleukin-6; TNF- $\alpha$, tumor necrosis factor- $\alpha$; VEGF, vascular endothelial growth factor; SCC, squamous cell carcinoma; OCT, optical coherence tomography; RCM, reflectance confocal microscopy; CLSM, confocal laser scanning microscopy

Key words: basal cell carcinoma, subtypes, dermoscopy, pathology, optical coherence tomography, reflectance confocal microscopy squamous counterpart. It has low mortality and extremely low metastatic rates (although when present, it indicates a poor patient prognosis); it also has a high morbidity rate through local destruction and recurrence, particularly when perineural invasion is observed, clinically or histopathologically. BCC development is the result of environmental and patient factors, with genetics and ultraviolet radiation playing major roles. The clinical and histopathological aspects vary according to tumor subtype, being classified as high-risk tumors (nodular, superficial, pigmented and infundibulocystic BCC with adnexal differentiation) and fibroepithelial subtypes, or as high-risk tumors (micronodular, infiltrating, sclerosing/morphoeic and basosquamous subtype or the type with sarcomatoid differentiation). Dermoscopy is now complimented by novel in vivo diagnostic tools (optical coherence tomography, reflectance confocal microscopy, high-resolution ultrasonography, Raman spectroscopy or terahertz pulse imaging), improving the diagnostic accuracy and providing tumor depth and lateral margins without the use of invasive techniques. Novel treatment approaches for the treatment of BCC have recently been investigated with the use of hedgehog pathway inhibitors, such as Vismodegib. These approaches aim for complete resolution, minimal side-effects, high patient satisfaction with the optimal cosmetic results, particularly in key areas, such as the face. The present review article summarizes and discusses 
the comprehensive clinical and histopathological aspects of $\mathrm{BCC}$, and presents novel imaging tools and therapeutic approaches that have been identified.

\section{Contents}

1. Introduction

2. Pathogenesis and risk factors

3. Clinical aspects

4. Histopathology

5. Dermoscopy

6. Novel diagnostic approaches

7. Treatment

8. Conclusions

\section{Introduction}

The skin is the largest organ of the human body and it is the site from which various types of tumors may arise, from benign ones, such as seborrheic keratosis, nevi and spiradenomas (some of which are considered even precursor lesions for their malignant counterparts) to malignant masses, such as basal cell carcinomas (BCCs) or squamous cell carcinomas (SCCs), melanomas or spiradenocarcinomas.

BCCs are one of the most common malignant tumors worldwide with skin involvement, being part of non-melanoma skin cancers, alongside SCCs, with which it can coexist in the same lesion, evolving at the site of a burn scar, or even from a benign tumor-like lesion, such as a verruca vulgaris (1-4). According to the World Health Organization (WHO), BCCs represent malignant tumors which have originated from basal cells found in the inter-follicular epidermis or in the hair follicle. BCC cases further increase the burden to global cancer cases which are constantly on the rise; it is estimated that 1 in 5 males and 1 in 6 females will suffer from one form of cancer during their lifetime $(5,6)$. Although the reporting of BCC cases is not precise (data are rarely collected), its global incidence is increasing, affecting approximately one million new patients each year. It is one of the most common types of skin cancer in certain populations such as among individuals of Asian, African or Hispanic origin (7).

BCC has low mortality and extremely low metastatic rates (although when present, it indicates a poor prognosis). However, it has a high morbidity rate, exemplified through local destruction and recurrence, particularly when perineural invasion (PNI) is present, allowing BCC to spread in a contiguous manner with secondary neuropathy. Extremely rare cases from the literature (11 in total) have reported BCC with intravascular invasion, having higher metastatic rates than BCC cases without this aggressive trait (8-11).

\section{Pathogenesis and risk factors}

BCC pathogenesis is the direct result of interactions between environmental factors and patient characteristics, as well as genetic factors. As regards genetics, the aberrant activation of the Hedgehog signaling pathway has been shown to be pathognomonic for BCC development and it can interact with other oncogenic pathways, such as EGFR, TGF- $\beta$, PI3K, NF- $\kappa \mathrm{B}$ and atypical protein kinase $\mathrm{C}$ (aPKC) $(9,12)$.

The risk factors incriminated in $\mathrm{BCC}$ development are classified as follows: Modifiable risk factors, such as ultraviolet (UV) radiation and behavioral factors associated with an increased exposure to this type of radiation (multiple sunburns at an early age and occupational sun exposure), being the most incriminating one; and non-modifiable risk factors, such as the elderly/aging population (with cumulative sun exposure), a positive family history of BCC and genetic factors, such as mutations of the patched tumor suppressor genes 1 and 2 (PTCH1 and PTCH2), which can be inherited as an autosomal dominant trait or can appear de novo, in the basal cell nevus syndrome/nevoid BCC syndrome/Gorlin-Goltz syndrome; other genetic syndromes associated with BCC development, such as xeroderma pigmentosum and Bazex-Dupré-Christol syndrome. The non-modifiable factors which are mainly incriminated in $\mathrm{BCC}$ development in the Caucasian population are the following: A fair skin (Fitzpatrick skin types I and II), a light eye color, blonde/red hair, freckles, photosensitizing medication (tetracyclins, hydrochlorothiazide and statins) and exposure to carcinogenic substances (such as arsenic). Along with other skin pathologies (Kaposi's sarcoma, herpes zoster, oral candidiasis or hairy leucoplakia), BCC has been observed to develop with a 2- and 5-fold increased frequency in patients who are human immunodeficiency virus (HIV)-positive and, respectively, in those who have received organ transplants $(7,9,13-18)$.

As the main factor responsible for the development of BCC, UV radiation exposure has been found to be responsible for the release of interleukin (IL)-6 and tumor necrosis factor- $\alpha$ (TNF- $\alpha$ ) from keratinocytes. In some benign and malignant tumors or in certain conditions, IL-6 is known to function as a growth factor [acquired immunodeficiency syndrome (AIDS), Kaposi's sarcoma, multiple myeloma, renal cell carcinoma, some T-cell or B-cell lymphomas], while also preventing apoptosis and inducing the expression of the anti-apoptotic protein, Bcl-xL. At the same time, IL-6 stimulates vascular endothelial growth factor (VEGF) expression in various cells, functioning as a pro-angiogenic factor by enhancing angiogenesis. Thus, IL-6 is incriminated in the pathogenesis of BCC $(19,20)$. Neuroactive factors seem to also play a role not only in BCC, but also in SCC development; the interactions between the peripheral nervous system and skin cells are mediated by several locally secreted, possibly stress-induced neuroendocrine factors, such as substance $\mathrm{P}$, catecholamines, somatostatin, calcitonin gene-related peptide or neurohormones (proopiomelanocortin, adrenocorticotropin and $\alpha$-melanocyte-stimulating hormone). These substances which are dysregulated by chronic stress have been found to be involved in the development and progression of $\mathrm{BCC}$ and SCC, by their involvement in immune system suppression and by ensuring a favorable tumor microenvironment (21).

$\mathrm{BCC}$ arising in uncommon locations, such as the oral cavity or the vulva is not associated with UV radiation exposure as a primary risk factor, as these are sun-protected areas. In such rare primary site cases, other risk factors are involved, such as chronic inflammation, immune suppression, Paget's disease of the vulva or lichen sclerosus, addressing the genital location; as regards the oral cavity, risk factors for BCC development remain 
unknown (22-24). Although vitiligo may be a predisposing factor for sunburn, and it may potentiate the effects of UV radiation and subsequent consequences, the available data reveal the contrary, a protective effect; the association between vitiligo and BCC is rare, as it is also in the case of melanoma (25-28).

\section{Clinical aspects}

BCC may have a wide array of clinical presentations; its medico-social importance resides in its prevalence, its detrimental effects on health and associated complications, as well as in its psychological burden, as with other pathologies (such as diabetes or other tumors). Oftentimes, patients suffering from BCC may present with a lesion which has enlarged with time, is non-healing and which may bleed or ulcerate; these aspects may also be accompanied by pruritus. The classical clinical description of such a tumor is that of a shiny, pearly, smooth papule/nodule with conspicuous, dilated and arborizing blood vessels, often with erosions or ulcerations and rolled margins. The clinical aspects vary with the histological type of the tumor (discussed below); thus, the classical clinical description may correspond to the nodular type of BCC, while the discovery of a circumscribed, annular, thin patch or plaque with/without scales, central clearing and rolled borders can be observed in superficial BCC; scar-like lesions or poorly defined, infiltrative, shiny plaques (which can be flat or depressed) can indicate the presence of an infiltrative or morphoeic/sclerosing BCC, and the pigmented variant of BCC can be clinically confused with melanoma or Spitz-Reed nevus. The fibroepithelial variant of BCC is frequently mistaken for an acrochordon or a seborrheic keratosis, presenting as sessile plaque or pedunculated papule or nodule, which can be flesh-colored or erythematous. Infundibulocystic BCCs present as pearly papules that are well circumscribed, being frequently mistaken for benign follicular processes $(1,5,29-31)$.

\section{Histopathology}

The histopathology of BCC is largely characterized by aggregates of basal cells with a small cytoplasm and large, hyperchromatic nuclei, apoptotic cells, all included in a fibromyxoid stroma, with tumor retraction spaces. Angiogenesis is an indicator of tumor development and its progression; the stroma surrounding BCC also reveals increased numbers of microvessels, being associated with local aggressive behavior $(1,5,32)$.

The BCC histopathologic subtypes are classified according to the risk of tumor recurrence; BCCs with a low risk of recurrence are nodular, superficial, pigmented and infundibulocystic (BCC with adnexal differentiation) and fibroepithelial. However, those with a high risk of are recurrence are micronodular, infiltrating, sclerosing/morphoeic and basosquamous $\mathrm{BCCs}$, and BCCs with sarcomatoid differentiation.

Nodular BCC presents microscopically as large nests or islands of malignant basaloid cells with central, haphazard cell arrangement and peripheral palisading, tumor-stroma clefting, mucoid/myxoid stroma with spindle cells, with/without amyloid deposits; sometimes the tumor stroma has a collagenous, keloidal-type aspect. The malignant tumor nests extend deep into the dermis and apoptotic cells can be found centrally. Nodular BCC has several subtypes, according to the secondary

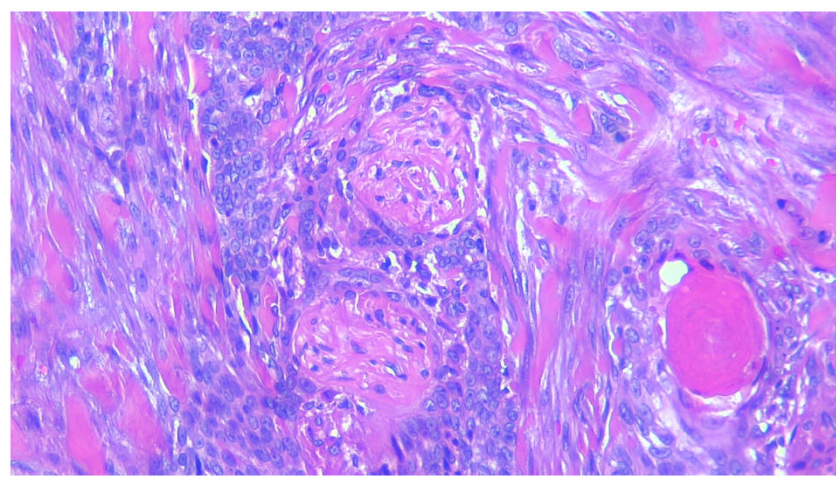

Figure 1. Keratotic basal cell carcinoma with perineural invasion. Hematoxylin and eosin staining of tissue was from an elderly Caucasian female, with a lesion on the face. Magnification, x200.

findings that characterize such tumors, keratotic (with mature keratin deposits found central in the tumor islands, Fig. 1), cystic/nodulocystic (cystic degeneration) and adenoid (with cribriform arrangement of tumor nests) $(1,5,33)$.

Superficial BCC (Fig. 2) develops as small islands or lobules of malignant basaloid cells with peripheral palisading, localized in the superficial dermis, with a connection to the epidermis and within a myxoid stroma, associated with a lichenoid, band-like, inflammatory infiltrate. It can appear as a multicentric tumor and may sometimes be part of a mixed-pattern tumor, with micronodular, nodular, or infiltrating components $(1,5,34)$.

Micronodular BCC is characterized by small islands or nests of malignant tumor cells which infiltrate deep into the dermis, sometimes even into the subcutaneous tissue; the tumor has a satellite-like arrangement of discrete nodules with irregular contours, lined by a thin margin of stroma and separated by normal dermal collagen $(1,5,35)$.

Infiltrating $\mathrm{BCC}$ is a subtype composed mainly of chords or thin nests of tumor cells (with a thickness of $>5-8$ cells) which infiltrate deeply, with angulated edges and have an irregular, permeating invasion pattern at the tumor edge. It frequently overlaps with morphoeic/sclerosing BCC and can be found with a nodular component $(1,5,35)$.

Sclerosing/morphoeic BCC is comprised of very thin strands/chords of tumor cells (with a thickness of 1-5 cells, and also with angulated ends) found in a collagenous type of stroma, with seldom tumor-stroma clefting. It infiltrates deeply and differs from the infiltrating subtype of BCC by the stromal characteristics, the latter lacking the highly collagenous stroma $(1,5,34)$.

Basosquamous carcinoma (metatypical BCC, Fig. 3) is a subtype characterized by the presence of both BCC and SCC tumor features, with transition areas between the two. The tumor nests are comprised of basaloid cells, which are intermingled with atypical squamous cells with eosinophilic cytoplasm which are dispersed or have a focal distribution; the stroma is oftentimes highly cellular, with a fibrotic appearance $(1,5,36)$.

Pigmented BCC is a variant of nodular or superficial BCC, which contains melanin pigment derived from an increased number of dendritic melanocytes within the malignant tumor nests, being found within the malignant basaloid cells or the macrophages which surround the malignant proliferation $(1,5,37)$. 


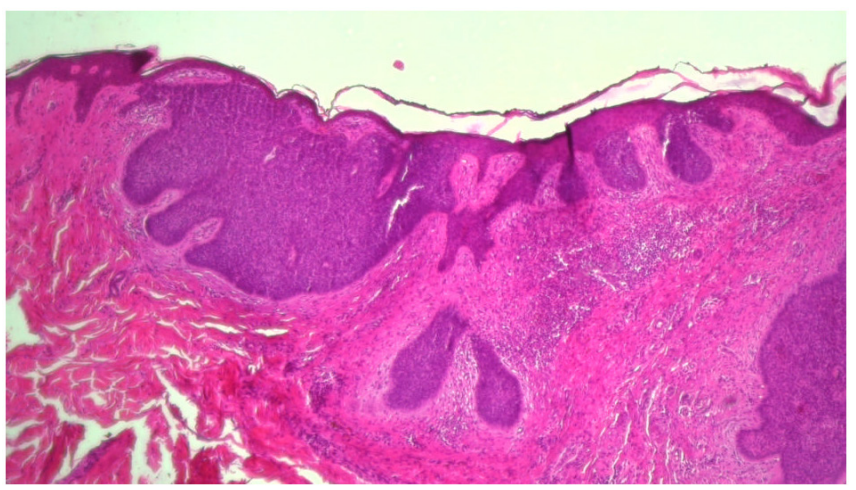

Figure 2. Mixed basal cell carcinoma with superficial multicentric and nodular components, associated with dense inflammatory infiltrate Hematoxylin and eosin staining of tissue from elderly Caucasian male, with a lesion on the head and neck region. Magnification, $\mathrm{x} 40$.

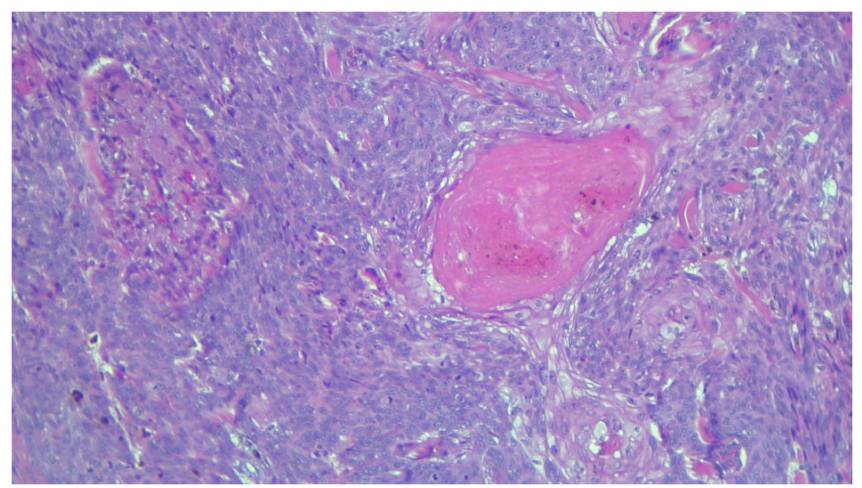

Figure 3. Partial view of a basosquamous carcinoma. Hematoxylin and eosin staining of elderly Caucasian male, with a lesion on the face. Magnification, $\mathrm{x} 100$.

BCC with sarcomatoid differentiation (metaplastic carcinoma) is characterized by a malignant proliferation of basaloid cells found within a sarcomatous stroma with variable histology. The malignant mesenchymal stromal component can take the form of an osteosarcoma, chondrosarcoma, leiomyosarcoma, pleomorphic undifferentiated sarcoma, or rhabdomyosarcoma $(1,5)$.

BCC with adnexal differentiation defines a subtype of BCC which is frequently found in the skin around the eyes, exhibiting differentiation towards follicular, eccrine, apocrine or sebaceous glands. Matrical differentiation in BCC is revealed by the presence of shadow cells; the infundibulocystic variant is characterized by the presence of small infundibular cyst-like spaces inside the tumor nodules; mature sebocytes can be found in $\mathrm{BCC}$ with sebaceous differentiation, while ductal structures, such as those found in eccrine and apocrine glands (and decapitation secretion in apocrine differentiation) are found in BCC with differentiation towards eccrine or apocrine sweat glands $(1,5,38)$.

Fibroepithelial BCC (fibroepithelioma of Pinkus or Pinkus tumor) is a distinct variant composed of thin strands of anastomosing basaloid cells with reticular pattern of development, linked to the epidermis and within a fibroblastic stroma. Sometimes rare basaloid islands can be found $(1,5,39)$.

\section{Dermoscopy}

Dermoscopy is a non-invasive skin examination procedure which allows the clinician to observe certain lesional characteristics which are not visible to the naked eye. The BCC examination and its positive diagnosis rely on three main features: Vascular structures (arborizing vessels and pigmented structures), nests with a blue-gray coloration and ovoid shape and the presence of ulcerations; these three features, along with features of melanocytic lesions (network areas) indicate the positive clinical diagnosis of BCC. This in vivo technique has a sensitivity of $89-91.2 \%$ and a specificity of $95 \%(34,40-42)$.

The dermoscopic features indicative of BCC are the following: Arborizing vessels (the most prevalent feature), a dotted or corkscrew appearance, or glomerular vascularization, short and fine telangiectasia; shiny and white structures which alternate with shiny white and red areas without a certain structure; nests with blue-gray coloration and ovoid shape, multiple blue and gray globules/dots (Table I). These features vary in prevalence and distribution among BCC subtypes, with certain other characteristics being found in those subtypes, such as concentric, spoke wheel structures or leaf-like areas in nodular BCC, while morpheaform BCC rarely presents with pigmentation.

The overall dermoscopic aspect of BCC is represented by the mixture of the abovementioned features, with variation according to the patient's age, sex, race, BCC subtype, tumor location or the presence or absence of pigmentation (40-42).

\section{Novel diagnostic approaches}

In recent years, novel technologies have been developed for the diagnosis of $\mathrm{BCC}$; some of these technologies are non-invasive, such as optical coherence tomography (OCT) and reflectance confocal microscopy (RCM), which are both in vivo diagnostic tools.

RCM uses a near-infrared laser in order to obtain images of thin sections of the skin; the light is reflected back from the selected focal point and enters the detector through a special pinhole. It is a highly sensitive (sensitivity varying between 100 and 91.7\%) and specific (specificity varying between 91.3 and $88.5 \%$ ) technique. This technique has the capacity for high resolution imaging, which is equivalent to 30 -fold the magnification of an optical microscope; however, it can only penetrate to depths of $250 \mu \mathrm{m}$ and does not have the capacity to evaluate tumor depth margins and invasion (12,43-48).

$\mathrm{RCM}$ criteria indicative of a BCC diagnosis can be found in the superficial dermis (or at the dermo-epidermal junction) and these include dark silhouettes (hyporeflective zones surrounded by bright collagen bundles, bright tumor islands which are often limited by a dark cleft, dendritic cells, plump, bright cells and canalicular vessels). As regards superficial $\mathrm{BCC}$, features which are indicative of its diagnosis are epithelial chords connected to the epidermis; nodular BCC has an additional increased vascular density, while aggressive BCC subtypes are evidenced by hyporeflective areas (12,43-49).

OCT uses infrared light in order to obtain a real-time image of the examined skin; the technique is based on the sum of light refractions of different skin components, with various optical properties; it is capable of examining the skin 
Table I. Dermoscopic features of basal cell carcinoma.

Vascular structures

Arborizing vessels

Short and fine telangiectasia

Dotted vascularization

'Corkscrew' vascularization

Glomerular vascularization

Concentric, spoke wheel structures

Leaf-like areas

Pigmented structures

Other features

Ovoid nests with blue-gray coloration

Shiny, white structures alternating with shiny white-red areas (no structure)

Multiple blue and gray globules/dots
Ulceration

Erosion/erosions at depths of $500 \mu \mathrm{m}$ (although at a depth $>400 \mu \mathrm{m}$ the image increases in noise and decreases in resolution). Its sensitivity is $87 \%$ and its specificity is $80 \%$. This technique has the capacity for deeper examination and is capable of en face and cross-sectional imaging; however, it has limited use for pigmented lesions $(12,43-48,50)$.

When identifying BCC with the help of OCT, the following images have been found to be positively associated with the diagnosis: Oval structures (with/without bright colored centers), dark areas bordering the dermis (hyporeflective area as the lateral tumor border), black zones or cones protruding into the adjacent dermis and disruption of the epidermal layering. For the nodular subtype of BCC, the most characteristic image is that of oval structures, with the presence of dark or black zones or cysts. For the superficial subtype, the presence of a dark area bordering the dermis and the bulges or cones extending from the epidermis to the dermis are the most characteristic and positively associated images. The image compared to 'a shoal of fish' which translates as elongated and narrow structures found in the dermis, is indicative of the infiltrative subtype of BCC $(12,43-48,50,51)$.

Both techniques can be combined for a more accurate diagnosis (resulting in line-field confocal OCT, combining the advantages of OCT, with vertical in-depth penetration and RCM with its high resolution) and can be accompanied by the classic dermoscopic examination, thus improving the accuracy of diagnosis (12,43-48).

Other techniques that can be used in the diagnosis of BCC are high-resolution ultrasonography, Raman spectroscopy or terahertz pulse imaging.

High resolution ultrasonography is a diagnostic tool using frequencies between $20-100 \mathrm{MHz}$, and it can measure the extent of the tumor, including its depth or thickness, while evaluating deep structure involvement. As regards the subtypes of BCC, the nodular one is described as dermal or hypodermal hypo-echoic nodules with various shapes (oval, irregular or ribbon-like shapes), with variably defined margins (well or ill-defined), some with or without an internal echo (which can be homogenous or non-homogenous) or with hyper-echoic spots. The superficial subtype has a less variable appearance, presenting as a hypo-echoic ribbon-like area, which is homogenous in appearance, without any internal echoes, posterior acoustic artifacts or hyper-echoic spots. The micronodular subtype of BCC is characterized by the presence of ill-defined, hypo-echoic tumor nodules located in the dermis, having internal echoes, some with hyper-echoic spots, with small, anechoic areas (cystic) or with posterior acoustic artifact. Infiltrative BCC has similar characteristics, also having ill-defined, hypo-echoic tumor nodules, but which were located both in the dermis and hypodermis, with a number of internal hyper-echoic spots and without a posterior reinforcement artifact. Basosquamous BCC is described as having dermal and hypodermal ill-defined, hypo-echoic nodules with multiple internal, hyper-echoic spots, some internal anechoic zones and without posterior acoustic artifact. When using this diagnostic tool, careful attention should be paid as tumor thickness is frequently overestimated, and the inflammatory infiltrate which is found at the base of the tumor nodules or islands may be confused as part of the tumor. However, this technique yields promising results in the pre-operative diagnosis of $\mathrm{BCC}$, revealing important tumor traits, such as tumor depth, associated lesions or margins $(52,53)$.

Raman spectroscopy is an optical technique which analyzes the vibrational molecule modes, and, apart from the other techniques used for BCC diagnosis, it offers a special focus on tumor vascularization.

Terahertz pulse imaging is a portable ex vivo or in vivo diagnostic tool which uses terahertz radiation, an electromagnetic spectrum found between the infrared and microwave regions, having the ability to evaluate the low-frequency type, vibrational and torsional motions in molecular systems and registering its absorption. Studies have registered spectroscopic differences between the normal tissue and that which is affected by a tumor process, meaning that that the absorption coefficient and refractive index are higher in areas affected by BCC, which are consistent with a higher water content, providing information regarding the extent of the tumor (54-56).

In vivo confocal laser scanning microscopy (CLSM) is also an innovative technique which is currently used in studying the morphological course of a disease by repeated, high magnification examination, revealing its dynamic treatment response. It is currently used in the study of inflammatory skin diseases; however, it is a promising diagnostic and monitoring tool for skin tumors, allowing the close inspection of the body's immune response to the tumor and the response to the applied treatment. However, further studies are required in order to evaluate BCC from this perspective (57). 


\section{Treatment}

The surgical treatment of $\mathrm{BCC}$ is the main approach through which the entire tumor mass can be excised, and the cosmetic and functional aspects can be preserved, providing optimal results for the patient. The surgical excision needs to be made with at least 4-mm margins in low-risk BCC, whereas for high-risk ones, margins of at least $6 \mathrm{~mm}$ should be ensured.

Mohs micrographic surgery involves the complete excision of the BCC with a microscopic examination of the surgical margins. It is most frequently used in high-risk tumors, with higher rates for long-term cure. This approach has a high success rate, with dermatopathologists and Mohs surgeons agreeing on surgical excision margin clearance $(12,58)$.

Curettage or electrodessication are older techniques, recommended in superficial BCC or low-risk tumors, having the downside of not allowing a histopathological examination of surgical margins. It is recommended that these two techniques should not be used in parts of the body with terminal hair growth, such as the scalp, beard area, axillae, or pubis, due to the risk of tumor extension in the hair follicle $(12,59)$.

Cryosurgery uses freeze-thaw cycles in order to destroy the malignant tumor cells, and, as with curettage and electrodessication, does not allow the microscopic examination of tumor margins and is mostly recommended in low-risk cases, such as superficial BCC (12).

Photodynamic therapy is a two-step therapeutic approach; it involves the initial local application of a photosensitizing chemical substance (methyl aminolevulinate or aminolevulinic acid), followed by irradiation with the help of a light source. It determines oxidative damage in the tumor mass with the apoptosis and necrosis of tumor cells, along with vascular damage, and without having major effects on the surrounding normal tissue; it may be recommended in cases of periocular BCC, having a good function preservation and cosmetic outcome. However, this technique has high recurrence rates of up to $30.7 \%$ within 5 years, and is mainly recommended for superficial BCC $(12,60)$.

Radiotherapy is a less frequent treatment approach, being used for unresectable tumors or in cases where surgery is not recommended; brachytherapy and external beam radiotherapy/teletherapy have been used in the treatment of BCC, having lower recurrence rates as compared with cryosurgery (12).

Topical treatments, such as 5-fluorouracil or imiquimod $5 \%$ applications, are recommended in superficial BCC subtypes and have registered histologic clearances ranging from $76-100 \%$, in 6 to 12 weeks of treatment. The study by Williams et al (61) reported the higher effectiveness of surgical treatment over imiquimod 5\% topical applications, with recurrences being observed as early as 1 year post-treatment concerning the local treatment. The 5-year success rates were higher for the cases where surgical treatment was applied $(97.7 \%)$, as compared with those treated with imiquimod 5\% (82.5\%). However, this type of treatment may be associated with side-effects, such as erythema, erosions or swelling, affecting patient compliance and treatment effectiveness $(12,61)$.

Intralesional chemotherapy with 5-fluorouracil, bleomycin, IL-2 or interferons have registered variable results and can have local side-effects or even general ones, such as flu-like manifestations.
Laser therapy, such as superpulsed carbon dioxide laser therapy or pulsed neodymium-based laser therapy, can be used alone or in combination with other therapeutic approaches. It has proven to have small recurrence rates of up to $1.8 \%$ in 5 years, although it presents with local adverse effects, such as soreness, edema, hyperemia and scarring.

Hedgehog pathway inhibitors, such as Vismodegib, are used in surgically advanced tumors as neoadjuvant therapy, prior to Mohs micrographic surgery or radiotherapy, allowing the tumor to decrease in size. As is the case with other treatment agents, its long-term use is associated with adverse effects and in order to combat such effects, treatment interruptions of up to 8 weeks have been practiced $(12,62,63)$.

\section{Conclusions}

The diagnosis and characterization of BCC needs to be based on the clinical, imaging and histopathology features of the tumor mass, combined with the patient's characteristics, in order to select the most effective treatment option and yield optimal results with the highest disease-free intervals and lowest recurrence rates. BCC treatment aims for a complete resolution, with minimal side-effects and high patient satisfaction, aiming for optimal cosmetic results, particularly in key areas such as the face.

\section{Acknowledgements}

The authors wish to acknowledge that the present study was supported by the 'Dunarea de Jos' University of Galati, Romania, through the research center - Multidisciplinary Integrated Center of Dermatological Interface Research MIC-DIR (Centrul Integrat Multidisciplinar de Cercetare de Interfata Dermatologica - CIM-CID).

\section{Funding}

The present study was supported by the 'Dunarea de Jos' University of Galati through an internal grant (grant no. RF3668/01.10.2021).

\section{Availability of data and materials}

Not applicable.

\section{Authors' contributions}

EN, MC, CB, FN, DJS, ML and ALT were major contributors to the writing of the manuscript and the literature search. $\mathrm{EN}, \mathrm{MC}, \mathrm{CB}$ and FN were involved in all the stages of the study (conception, design, revision, data collection, critical analysis and language editing). DJS, ML and ALT contributed to the conception and design of the study, as well as in the study revision. EN, ALT, DJS and FN assisted in the collection of the data for the review article. LR, GL, VC and LA revised the study for important intellectual content. All authors have read and approved the final version of the manuscript to be published. EN and DJS confirm the authenticity of all the raw data. All authors agree to be accountable for all aspects of the work in ensuring that questions related 
to the accuracy or integrity of any part of the work. All authors have had equal participation, contribution and equal rights to this article.

\section{Ethics approval and consent to participate}

The present study was approved by the 'Sf. Apostol Andrei' Emergency Clinical Hospital Ethics Committee (decision no. 19758). The patients provided written informed consent for the publication of any associated data and accompanying image.

\section{Patient consent for publication}

Not applicable.

\section{Competing interests}

The authors declare that they have no competing interests.

\section{References}

1. Cameron MC, Lee E, Hibler BP, Barker CA, Mori S, Cordova M, Nehal KS and Rossi AM: Basal cell carcinoma: Epidemiology; pathophysiology; clinical and histological subtypes; and disease associations. J Am Acad Dermatol 80: 303-317, 2019.

2. Matsui Y, Makino T, Takemoto K, Kagoyama K and Shimizu T: Co-existence of basal cell carcinoma and squamous cell carcinoma in a single burn scar region. Burns Open 4: 64-66, 2020.

3. Lai K, Chan E and Ko SC: Combination of squamous cell carcinoma and basal cell carcinoma arising from a giant verruca vulgaris involving the eyelid. Am J Ophthalmol Case Rep 21: $100858,2020$.

4. Rebegea LF, Firescu D, Dumitru M and Patrascu A: Skin spiradenocarcinoma-case presentation. Rom J Morphol Embryol 57: 327-330, 2016.

5. Messina J, Epstein EH Jr, Kossard S, McKenzie C, Patel RM, Patterson JW and Scolyer RA: Chapter 1-Keratinocytic/epiderma tumors. Basal cell carcinoma. In: WHO Classification of skin tumors. Elder DE, Massi D, Scolyer RA and Willemze R (eds). 4th edition. International Agency for Research on Cancer, Lyon, pp26-24, 2017.

6. Rebegea L, Firescu D, Baciu G and Ciubara A: Psycho-oncology support. Brain 10: 77-88, 2019

7. Hogue L and Harvey VM: Basal cell carcinoma, squamous cell carcinoma, and cutaneous melanoma in skin of color patients. Dermatol Clin 37: 519-526, 2019.

8. Poignet B, Gardrat S, Dendale R, Lemaitre S, LumbrosoLe Rouic L, Desjardins L, Cassoux N and Levy Gabriel C: Basal cell carcinomas of the eyelid: Results of an initial surgical management. J Fr Ophtalmol 42: 1094-1099, 2019.

9. Kim DP, Kus KJB and Ruiz E: Basal cell carcinoma review. Hematol Oncol Clin North Am 33: 13-24, 2019.

10. Ashraf DC, Kalin-Hajdu E, Levin MH and Kersten RC: Mixed cranial neuropathies due to occult perineural invasion of basal cell carcinoma. Am J Ophthalmol Case Rep 13: $136-139,2018$.

11. Muzumdar S, Stewart CL and Feng H: Rare case of a basal cell carcinoma with intravascular invasion. Int J Womens Dermatol 6 : 334-335, 2020.

12. Fania L, Didona D, Morese R, Campana I, Coco V, Di Pietro FR, Ricci F, Pallotta S, Candi E, Abeni D and Dellambra E: Basal cell carcinoma: From pathophysiology to novel therapeutic approaches. Biomedicines 8: 449, 2020.

13. Nicoara M, Bain K, Patel R, Jaikaran O, Hingorani A and Asher E: Malignant transformation of nonhealing ulcer-basal cell carcinoma. Ann Vasc Surg 70: 565.e7-565.e10, 2021.

14. Coulombe C, Gagnon LP, Larouche V and Dionne MC: Infantile-onset palmo-plantar basal cell carcinomas and pits in Gorlin syndrome. JAAD Case Rep 4: 662-664, 2018.

15. Nwabudike LC and Tatu AL: Response to-Chronic exposure to tetracyclines and subsequent diagnosis for non-melanoma skin cancer in a large Mid-Western US population. J Eur Acad Dermatol Venereol 32: e159, 2018.
16. Tatu AL, Ciobotaru OR, Miulescu M, Buzia OD, Elisei AM, Mardare N, Diaconu C, Robu S and Nwabudike LC: Hydrochlorothiazide: Chemical structure, therapeutic, phototoxic and carcinogenetic effects in dermatology. Rev Chim (Bucharest) 69: 2110-2114, 2018.

17. Nwabudike LC, Elisei AM, Buzia OD, Miulescu M and Tatu AL: Statins. A review on structural perspectives, adverse reactions and relations with non-melanoma skin cancer Rev Chim (Bucharest) 69: 2557-2562, 2018.

18. Draganescu M, Baroiu L, Iancu A, Dumitru C, Radaschin D, Polea ED, Bobeica C, Tatu AL, Niculet E and Fekete GL: Perspectives on skin disorder diagnosis among people living with HIV in southeastern Romania. Exp Ther Med 21: 97, 2021.

19. Niculet E, Chioncel V, Elisei AM, Miulescu M, Buzia OD, Nwabudike LC, Craescu M, Draganescu M, Bujoreanu F, Marinescu E, et al: Multifactorial expression of IL-6 with update on COVID-19 and the therapeutic strategies of its blockade (Review). Exp Ther Med 21: 263, 2021.

20. Jee SH, Shen SC, Chiu HC, Tsai WL and Kuo ML: Overexpression of interleukin-6 in human basal cell carcinoma cell lines increases anti-apoptotic activity and tumorigenic potency. Oncogene 20: 198-208, 2001

21. Lupu M, Caruntu A, Caruntu C, Papagheorghe LML, Ilie MA, Voiculescu V, Boda D, Constantin C, Tanase C, Sifaki M, et al: Neuroendocrine factors: The missing link in non melanoma skin cancer (Review). Oncol Rep 38: 1327-1340, 2017.

22. McEnery-Stonelake ME, Clark MA and Vidimos AT: Vulvar basal cell carcinoma arising in the setting of repeated perilamp exposure. JAAD Case Rep 6: 103-105, 2020.

23. Varadarajan VV, Nasri E and Dziegielewski PT: Basal cell carcinoma of the oral cavity: A case report. Otolaryngol Case Rep 15: 100159, 2020.

24. Tatu AL and Nwabudike LC: The treatment options of male genital lichen sclerosus et atrophicus short title for a running head: Treatments of genital lichen sclerosus. In: Proceedings of the 14th National Congress of Urogynecology and the National Conference of the Romanian Association for the Study of Pain, pp262-264, 2017.

25. Rustemeyer J, Günther L and Deichert L: A rare association: Basal cell carcinoma in a vitiliginous macula. Oral Maxillofac Surg 15: 175-177, 2011.

26. Mihăilă B, Dinică RM, Tatu AL and Buzia OD: New insights in vitiligo treatments using bioactive compounds from Piper nigrum. Exp Ther Med 17: 1039-1044, 2019.

27. Fiszon-Cerqueira L, Ramos-E-Silva M, Guerreiro FB, Cistaro-Serrano M, Carneiro AHC and Gomes MK: Giant basal cell carcinoma associated with vitiligo. Clin Case Rep 7: 1782-1786, 2019.

28. Byrne KT and Turk MJ: New perspectives on the role of vitiligo in immune responses to melanoma. Oncotarget 2: 684-694, 2011.

29. Nwabudike LC, Tebeica T and Tatu AL: Nodular, ulcerated seborrheic keratosis. Clin Exp Dermatol 45: 602-604, 2020.

30. Tatu AL: Umbilicated blue black lesion on the lateral thorax. J Cutan Med Surg 21: 252, 2017.

31. Earar K, Sirbu I, Onisor C and Luca E: Oral rehabilitation on implants and introduction of pathogenic mechanisms in relation to oral implants-sugar diabetes. Rev Chim (Bucharest) 70: 3750-3752, 2019.

32. Lupu M, Caruntu C, Popa MI, Voiculescu VM, Zurac S and Boda D: Vascular patterns in basal cell carcinoma: Dermoscopic, confocal and histopathological perspectives. Oncol Lett 17: 4112-4125, 2019

33. Căruntu C, Boda D, Guţu DE and Căruntu A: In vivo reflectance confocal microscopy of basal cell carcinoma with cystic degeneration. Rom J Morphol Embryol 55: 1437-1441, 2014.

34. Mackiewicz-Wysocka $M$, Bowszyc-Dmochowska M, Strzelecka-Węklar D, Dańczak-Pazdrowska A and Adamski Z: Basal cell carcinoma-diagnosis. Contemp Oncol (Pozn) 17: 337-342, 2013.

35. Dourmishev LA, Rusinova D and Botev I: Clinical variants, stages, and management of basal cell carcinoma. Indian Dermatol Online J 4: 12-17, 2013.

36. Lima NL, Verli FD, de Miranda JL and Marinho SA: Basosquamous carcinoma: Histopathological features. Indian J Dermatol 57: 382-383, 2012.

37. Abudu B and Cohen PR: Pigmented basal cell carcinoma masquerading as a melanoma. Cureus 11: e4369, 2019. 
38. Shash HA, Almarzouq SF, Alghamdi AA and Alratroot JA: Basal cell carcinoma with sebaceous differentiation: A case report and review of literature. Plast Reconstr Surg Glob Open 8: e3234, 2020

39. Haddock ES and Cohen PR: Fibroepithelioma of pinkus revisited. Dermatol Ther (Heidelb) 6: 347-362, 2016.

40. Reiter O, Mimouni I, Gdalevich M, Marghoob AA, Levi A, Hodak E and Leshem YA: The diagnostic accuracy of dermoscopy for basal cell carcinoma: A systematic review and meta-analysis. J Am Acad Dermatol 80: 1380-1388, 2019.

41. Reiter O, Mimouni I, Dusza S, Halpern AC, Leshem YA and Marghoob AA: Dermoscopic features of basal cell carcinoma and its subtypes: A systematic review. J Am Acad Dermatol 85: 653-664, 2019.

42. Álvarez-Salafranca M,Ara MandZaballos P: Dermoscopy in basal cell carcinoma: An updated review. Actas Dermosifiliogr 112: 330-338, 2021

43. Cameron MC, Lee E, Hibler BP, Giordano CN, Barker CA, Mori S, Cordova M, Nehal KS and Rossi AM: Basal cell carcinoma: Contemporary approaches to diagnosis, treatment, and prevention. J Am Acad Dermatol 80: 321-339, 2019.

44. Suppa M, Fontaine M, Dejonckheere G, Cinotti E, Yélamos O, Diet G, Tognetti L, Miyamoto M, Orte Cano C, Perez-Anker J, et al: Line-field confocal optical coherence tomography of basal cell carcinoma: A descriptive study. J Eur Acad Dermatol Venereol 35: 1099-1110, 2021.

45. Holmes J, von Braunmühl T, Berking C, Sattler E, Ulrich M, Reinhold U, Kurzen H, Dirschka T, Kellner C, Schuh S and Welzel J: Optical coherence tomography of basal cell carcinoma: Influence of location, subtype, observer variability and image quality on diagnostic performance. Br J Dermatol 178 $1102-1110,2018$

46. Hussain AA, Themstrup L and Jemec GB: Optical coherence tomography in the diagnosis of basal cell carcinoma. Arch Dermatol Res 307: 1-10, 2015.

47. Lupu M, Popa IM, Voiculescu VM, Boda D, Caruntu C, Zurac S and Giurcaneanu C: A retrospective study of the diagnostic accuracy of in vivo reflectance confocal microscopy for basal cell carcinoma diagnosis and subtyping. J Clin Med 8: 449, 2019.

48. Ghita MA, Caruntu C, Rosca AE, Kaleshi H, Caruntu A, Moraru L, Docea AO, Zurac S, Boda D, Neagu M, et al: Reflectance confocal microscopy and dermoscopy for in vivo, non-invasive skin imaging of superficial basal cell carcinoma. Oncol Lett 11: 3019-3024, 2016

49. Sahu A, Yélamos O, Iftimia N, Cordova M, Alessi-Fox C, Gill M, Maguluri G, Dusza SW, Navarrete-Dechent C, González S, et al: Evaluation of a combined reflectance confocal microscopy-optical coherence tomography device for detection and depth assessment of basal cell carcinoma. JAMA Dermatol 154: 1175-1183, 2018.

50. Reddy N and Nguyen BT: The utility of optical coherence tomography for diagnosis of basal cell carcinoma: A quantitative review. Br J Dermatol 180: 475-483, 2019.

51. Navarrete-Dechent C, Rajadhyaksha M and Nehal KS: Can optical coherence tomography improve the management of basal cell carcinoma? Br J Dermatol 180: 448-449, 2019.
52. Wang SQ, Liu J, Zhu QL, Zhao CY, Qu T, Li F, Wortsman X and Jin HZ: High-frequency ultrasound features of basal cell carcinoma and its association with histological recurrence risk. Chin Med J (Engl) 132: 2021-2026, 2019.

53. Bobadilla F, Wortsman X, Muñoz C, Segovia L, Espinoza M and Jemec GB: Pre-surgical high resolution ultrasound of facial basal cell carcinoma: Correlation with histology. Cancer Imaging 8: 163-172, 2008.

54. Wallace VP, Fitzgerald AJ, Pickwell E, Pye RJ, Taday PF, Flanagan N and Ha T: Terahertz pulsed spectroscopy of human Basal cell carcinoma. Appl Spectrosc 60: 1127-1133, 2006.

55. Woodward RM, Cole B, Wallace VP, Arnone DD, Pye R, Linfield EH, Pepper M and Davies AG: Terahertz pulse imaging of in-vitro basal cell carcinoma samples. Technical Digest. Summaries of papers presented at the Conference on Lasers and Electro-Optics. Postconference Technical Digest (IEEE Cat. No. 01CH37170), 329-330, 2001.

56. Zhang J, Fan Y, Song Y and Xu J: Accuracy of Raman spectroscopy for differentiating skin cancer from normal tissue. Medicine (Baltimore) 97: e12022, 2018.

57. Ilie MA, Caruntu C, Lixandru D, Tampa M, Georgescu SR, Constantin MM, Constantin C, Neagu M, Zurac SA and Boda D: In vivo confocal laser scanning microscopy imaging of skin inflammation: Clinical applications and research directions (Review). Exp Ther Med 17: 1004-1011, 2019.

58. Cerci FB, Kubo EM and Werner B: Comparison of basal cell carcinoma subtypes observed in preoperative biopsy and Mohs micrographic surgery. An Bras Dermatol 95: 594-601, 2020.

59. Kopf AW, Bart RS, Schrager D, Lazar M and Popkin GL: Curettage-electrodesiccation treatment of basal cell carcinomas. Arch Dermatol 113: 439-443, 1977.

60. Li X, Tan L, Kou H, Zhang J, Wang Y, Li G and Lu Y: Ocular preservation through limited tumor excision combined with ALA-PDT in patients with periocular basal cell carcinoma. Photodiagnosis Photodyn Ther 27: 291-294, 2019.

61. Williams HC, Bath-Hextall F, Ozolins M, Armstrong SJ, Colver GB, Perkins W and Miller PSJ: Surgery versus imiquimod for nodular and superficial basal cell carcinoma (SINS) study group. surgery versus $5 \%$ imiquimod for nodular and superficial basal cell carcinoma: 5-year results of the SINS randomized controlled trial. J Invest Dermatol 137: 614-619, 2017.

62. Sabu DM, Kroes J, Gilham C, Fleming A and Kelleher FC: Neo-adjuvant Vismodegib followed by radiation in locally advanced basal cell carcinoma. Curr Probl Cancer: Apr 1, 2021 (Epub ahead of print).

63. Chanu P, Musib L, Wang X, Cheeti S, Girish S, Bruno R, Lu T, Reddy J, Jin JY and Caro I: Vismodegib efficacy in advanced basal cell carcinoma maintained with 8-week dose interruptions: A model-based evaluation. J Invest Dermatol 141: 930-933, 2021.

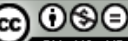

This work is licensed under a Creative Commons Attribution-NonCommercial-NoDerivatives 4.0 International (CC BY-NC-ND 4.0) License. 